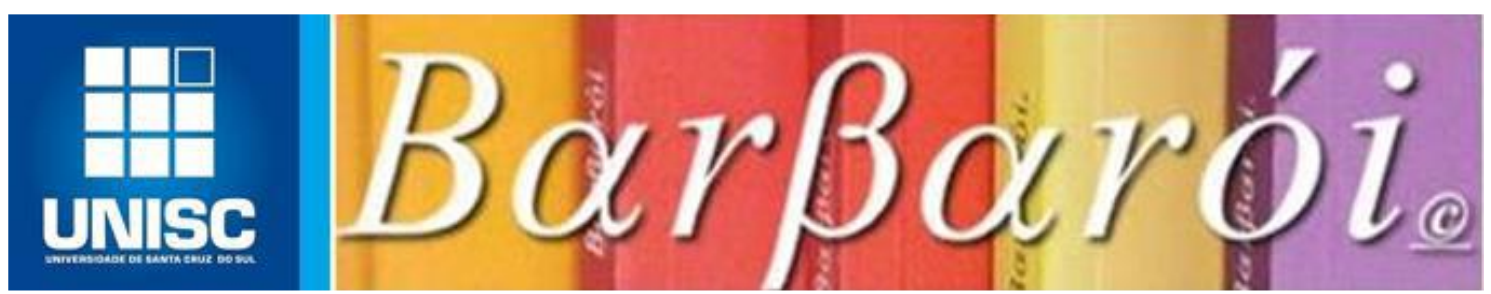

\title{
A IMPORTÂNCIA DO CONTROLE SOCIAL E DA PARTICIPAÇÃO DOS CONSELHOS MUNICIPAIS NAS POLÍTICAS DE COMBATE À POBREZA
}

DOI: http://dx.doi.org/10.17058/barbaroi.v0i0.13954

\author{
Fabiana Zanardi \\ Universidade Regional do Noroeste do Estado do Rio Grande do Sul - UNIJUÍ - Brasil \\ Airton Adelar Mueller \\ Universidade Regional do Noroeste do Estado do Rio Grande do Sul - UNIJUÍ - Brasil \\ Moisés de Oliveira Matusiak \\ Universidade Regional do Noroeste do Estado do Rio Grande do Sul - UNIJUÍ - Brasil \\ Edi Branco da Silva \\ Universidade Regional do Noroeste do Estado do Rio Grande do Sul - UNIJUÍ - Brasil

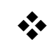

\section{Resumo}

O presente artigo tem como escopo a reflexão em torno da importância do controle social e da participação dos Conselhos Municipais nas políticas de combate à pobreza. Destaca-se o processo histórico e as principais conquistas e desafios na consolidação destes arranjos institucionais, ativos após a promulgação da Constituição Federal de 1988 e responsáveis por formular, acompanhar e fiscalizar as políticas públicas brasileiras. Para responder ao desafio proposto, o caminho metodológico conta com a abordagem qualitativa, com realização de pesquisa bibliográfica e documental partindo de contribuições teóricas clássicas e contemporâneas que abordam o tema, classificando o estudo como pesquisa exploratória. $\mathrm{O}$ recorte utilizado foi a Constituição Federal do ano de 1988 até o atual contexto de 2019. Na tentativa de promover maiores reflexões sobre o assunto, são problematizados neste trabalho as relações entre as normativas legais e sua implementação prática, por meio da análise de distintas concepções teóricas e do processo histórico da participação dos Conselhos Municipais junto às políticas de combate à pobreza. Os resultados da pesquisa indicam que mesmo estando consolidados mediante Legislação, muitos são os desafios no sentido de efetivar a participação do controle social na gestão das políticas de combate à pobreza. A legalização existe na teoria, porém, muito precisa ser construído para superar limitações e promover o exercício democrático da população por meio dos Conselhos Municipais na gestão das políticas públicas.

Palavras-Chave: Controle Social. Políticas Públicas. Conselhos Municipais. 


\section{Introdução}

No contexto brasileiro, apesar dos avanços ocorridos nas últimas décadas, a participação da sociedade civil na construção de políticas sociais públicas que atendam aos interesses da população ainda é considerada restrita, mesmo sendo uma das principais conquistas da Constituição Federal de 1988.

A expressão controle social possui uma multiplicidade de conceitos e classificações distintas, sendo historicamente compreendido como o controle exercido pelo Estado sobre a sociedade. Para Iamamoto e Carvalho (1982), o termo designa o meio usado pelo Estado para exercer dominação, servindo para realizar de forma técnica o controle das massas, a fim de impedir uma insubordinação da ordem pelos segmentos populacionais excluídos dos padrões considerados como adequados à realidade social.

Conforme Nogueira (2018), o tema do controle confunde-se com o do poder, pois é impossível imaginar política sem poder, sem potência capaz de acumular forças. Neste sentido, vale-se da possibilidade de um indivíduo ou grupo impor sua vontade no interior de uma relação social dominando eventuais resistências. $\mathrm{O}$ autor ainda destaca, que deste processo surgiu a "sociologia política de Weber: o poder (Macht) existe quando uma potência, valendo-se de determinados recursos, consegue fixar-se como dominação (Herrschaft) e ver suas ordens serem cumpridas" (NOGUEIRA, 2018, p. 196).

É válido considerar que até os anos de 1980, o uso da força física, política ou militar aliada a políticas compensatórias associadas a uma cultura paternalista foram quase que exclusivamente a forma de controle social praticada no Brasil, por diferentes instituições sociais especializadas em obter o consenso da população através de meios coercitivos ou persuasivos (IAMAMOTO; CARVALHO, 1982).

A organização e mobilização popular realizada na década de 80 , em busca de um estado democrático e garantidor do acesso universal aos direitos sociais, destacou a possibilidade de inversão do controle social, na perspectiva de exercício da sociedade civil sobre o Estado, legitimando a importância desta participação na implementação das políticas sociais (SILVA, et al., 2008).

A Constituição Federal de 1988 é o marco decisivo na notabilidade aos direitos sociais, pois ao inserir Saúde, Assistência Social e Previdência Social como políticas integrantes do sistema de seguridade social, instaurou o princípio da cidadania e da democracia como condutor e estabeleceu como modelo de sua organização a descentralização político-administrativa com a participação da população, por meio de organizações representativas, na formulação e controle de suas ações, em todos os níveis (BRASIL, 1988). 
Historicamente as políticas de combate à pobreza no Brasil estão associadas à assistência social, que mesmo legitimada pela Constituição Federal como direito social e política pública, possui um legado caracterizado por relações de favor e assistencialismo do poder público. Estes princípios nortearam profissionais e usuários por muito tempo, associados ao primeiro-damismo, representando um caráter de benesse, transformando o usuário na condição de assistido/favorecido e nunca como cidadão, usuário de uma política pública de direito. Da mesma forma confundia-se a assistência social com a caridade da igreja, com a ajuda aos pobres e necessitados. Assim, tradicionalmente a assistência social era reconhecida como assistencialista (YAZBEK, 2004).

A Assistência Social foi elaborada para intervir na pobreza e acabou funcionando como um governo paralelo da pobreza. Os programas foram direcionados para minimizar as carências das populações pobres, sem incluí-las nas políticas públicas; um governo “[...] sem compromisso de universalizar a proteção social e sem compromisso de garantir padrões de qualidade e de controle social" (CARVALHO, 1994, p. 88).

A participação social é uma das diretrizes estabelecidas pela Constituição Federal de 1988 para a organização das ações da Assistência Social, reforçadas pela Lei Orgânica da Assistência Social (LOAS), que dispõe sobre sua organização, instituindo em seu artigo 16 os Conselhos de Assistência Social em âmbito Nacional, Estadual e Municipal como instâncias de deliberação colegiada do SUAS - Sistema Único de Assistência Social, cuja composição deve ser paritária entre governo e sociedade civil (MDS, 2018).

Desta forma, a presença dos Conselhos na gestão das políticas públicas nas três esferas governamentais deve estar direcionada e operacionalizada iniciando no âmbito municipal, observando sua efetividade a partir de seus principais atores, os Conselheiros Municipais. É necessário, porém, não criar uma falsa ilusão sobre o poder dos conselhos, pois a sociedade civil é heterogênea e por isso é conflitiva, dinâmica e contraditória e sua participação não reflete sempre de forma direta sobre a supremacia de defesa dos interesses dos usuários. Estes, por sua vez, não conseguem ser auto representados, pois alguns possuem dificuldades de compreensão de termos técnicos utilizados e muitas vezes sua representação atende interesses de entidades prestadoras de serviços e até mesmo de gestores públicos (SILVA, et al., 2008).

Neste sentido, este estudo busca contribuir com o entendimento aprimorado da temática, apresentando uma sistematização crítico-reflexiva acerca da participação dos conselhos e do controle social nas políticas públicas de combate à pobreza no Brasil. Trata-se de um estudo qualitativo, com base em pesquisa bibliográfica e documental, de caráter Barbarói, Santa Cruz do Sul, n.54, p.<6-30>, jul./dez. 2019 
exploratório (GIL, 2017). Neste sentido, as fontes pesquisadas se referem a estudos científicos de autores clássicos e contemporâneos que abordam o assunto por meio da sociologia, economia, direito, administração e legislação, referindo distintos olhares sobre o tema. Também se pesquisou normativas legais e indicadores oficiais que discorrem sobre o conteúdo. Quanto à análise dos dados propôs-se elucidar as principais ideias e considerações teóricas apresentadas sinalizando a necessidade de reflexão dos leitores e principalmente proposição de novos estudos que possam explorar e aprofundar o tema.

Três são os tópicos apresentados neste estudo que são considerados essenciais para uma compreensão adequada do tema. Cada tópico é tratado em um capítulo específico do artigo. O primeiro deles trata-se de uma reconstituição histórica das distintas concepções de controle social, analisando a importância e a participação dos conselhos municipais na gestão pública local. Feito isso, na seção seguinte, parte-se para a reconstituição da trajetória histórica das políticas de combate à pobreza no Brasil, destacando os principais programas e serviços socioassistenciais e a participação dos Conselhos Municipais. Por fim, à luz dos itens anteriores, analisa-se avanços e desafios do controle social na superação das limitações que impedem ou dificultam o exercício democrático da gestão das políticas de combate à pobreza.

\section{Controle Social: Distintas concepções e a importância da participação dos Conselhos Municipais na Gestão Pública local}

O termo controle social tem origem na sociologia e costuma ser empregado para estabelecer os instrumentos que organizam a ordem social disciplinando a sociedade e submetendo os indivíduos a determinados padrões sociais e princípios morais. Desta forma, assegura a conformidade de comportamento das pessoas a um conjunto de regras e princípios prescritos e sancionados. Mannheim (1971, p. 178) define controle social como o "conjunto de métodos pelos quais a sociedade influencia o comportamento humano, tendo em vista manter determinada ordem”.

Conforme Correia (2008), o significado da expressão controle social na teoria política é confuso, pois pode ser concebido em sentidos diferentes a partir de concepções distintas de Estado e de sociedade civil. Pode ser utilizado para designar o controle do Estado sobre a sociedade, quanto para designar o controle da sociedade (ou de setores organizados na sociedade) sobre as ações do Estado.

Nogueira (2018) entende que a democracia não se sustenta sem um sistema composto por vontades e interesses, no qual ocorre a produção da ordem que se edifica sobre um conjunto de liberdades que preveem procedimentos de deliberação ampliada, pois não se vive 
numa ditadura. Desta forma, a democracia sugere que o poder esteja subordinado a algum tipo de controle, externo ou inerente a ele. Para o autor ainda, quanto mais organizada for uma sociedade que esteja consciente de seus interesses e reais possibilidades, maior será sua potência como agente de controle de poder. O controle social na democracia constitui-se como figura central, pois quando os cidadãos, a sociedade e os grupos organizados controlam o poder, eles mesmos detêm o poder.

Para Iamamoto e Carvalho (1988), na sociedade capitalista, o Estado tem exercido o controle social sobre o conjunto, em favor dos interesses da classe dominante para garantia do consenso em torno da aceitação da ordem do capital. Esse controle é realizado através da intervenção do Estado sobre os conflitos sociais imanentes da reprodução do capital, implementando políticas sociais para manter a atual ordem, difundindo a ideologia dominante e interferindo no "cotidiano da vida dos indivíduos, reforçando a internalização de normas e comportamentos legitimados socialmente" (IAMAMOTO; CARVALHO, 1988, p. 109).

Parafraseando Gramsci (1978), não existe uma oposição entre Estado e sociedade civil, mas uma relação orgânica, pois a oposição real se dá entre as classes sociais, pode-se compreender que o controle social acontece na disputa entre essas classes pela hegemonia na sociedade civil e no Estado. Desta forma, segundo a concepção gramsciniana, o Estado é “todo o conjunto de atividades práticas e teóricas com as quais a classe dirigente não só justifica e mantém o seu domínio, mas chega a obter o consenso dos governados" (GRAMSCI, 1978, p. 149).

De acordo com esta concepção, o Estado é o conjunto formado pela sociedade política mais a sociedade civil e exerce não apenas função coercitiva, mas outras funções culturais, políticas e econômicas. Nesse sentido, a sociedade civil importa para dentro do Estado necessidades diversas expressando muitas vezes interesses contraditórios aos defendidos pela classe dominante.

Assim sendo, apesar do Estado ser defensor da classe dominante na sociedade capitalista, também é influenciado por interesses da classe dominada, que dependendo da correlação de forças, poderá obter determinadas conquistas, mediante sua própria organização por meio de alianças e compromissos construídos com outros segmentos (SILVA, et al., 2008). Segundo as autoras, a política social se constitui uma das formas que o Estado usa para incorporar interesses da classe dominada, porém, a força do controle social por parte da sociedade civil organizada pode atribuir vigilância e fiscalização dos meios utilizados no seu atendimento, concretizando assim a democracia participativa. 
Parafraseando Vitale (2008), com base no artigo $1^{\circ}$ da $\mathrm{CF} / 88$, surgiram diversas previsões acerca da democracia participativa: abordando o âmbito do Poder Executivo, podese afirmar que a CF/88 estabelece uma relação entre participação e direitos sociais. Na esfera da seguridade social, por exemplo, a Constituição prevê o "caráter democrático e descentralizado da gestão administrativa, com a participação da comunidade, em especial de trabalhadores, empresários e aposentados" (art. 194, VII); na da assistência social, o texto constitucional refere-se à "participação da população, por meio de organizações representativas, na formulação das políticas e no controle das ações em todos os níveis" (art. 204, II).

Pimenta (2007), afirma que o princípio da democracia participativa é amplamente amparado pela $\mathrm{CF} / 88$, não se tratando de um rol taxativo, e sim de um sistema aberto a outras formas de participação popular. Para o autor, com a democracia participativa é praticado o princípio da transparência, diminuindo a distância entre o bem comum e os seus destinatários, sendo que a sociedade tem o direito de participar efetivamente da gestão pública, exteriorizando seus interesses e necessidades.

A participação social nas políticas do Estado pode ser incorporada a partir das Organizações Não Governamentais (ONG's), grupos de debate políticos regionais, associações populares e demais interessados. Entre os canais de participação social nas políticas públicas tem-se: os conselhos gestores, em todas as instâncias da federação, que deliberam ou são consultados sobre as temáticas que representam saúde, educação, habitação, assistência social, segurança alimentar e nutricional, etc (PAES DE PAULA, 2005).

Nesse sentido, diante da democracia participativa legitimada pela $\mathrm{CF} / 88$, os conselhos municipais são importantes instrumentos de reordenamento das políticas públicas, podendo se constituir em mediadores entre a população e o governo local, com o objetivo de formular, implementar, avaliar e fiscalizar estas políticas, as quais atenderão às necessidades sociais. Eles são instrumentos da democracia participativa, tendo como função o de trazer para o Governo os problemas reais da sociedade e auxiliar na resolutividade dos mesmos.

Como espaços democráticos de gestão do que é público, os Conselhos apesar de suas contradições e fragilidades, tem sua importância, num país como o Brasil, em que a cultura de submissão ainda está arraigada na maioria da população e em que o público é tratado como posse de pequenos grupos de privilegiados. O controle social, ou seja, o controle dos segmentos que representam as classes subalternas sobre as ações do Estado e sobre o destino dos recursos públicos torna-se um desafio importante na realidade brasileira para que se criem resistência à redução de políticas sociais, à sua privatização e à sua mercantilização (CORREIA, 2002, p. 41). 
Diante disso, os conselhos se constituem como arranjos institucionais importantes por meio dos quais a população pode participar e intervir no processo de gestão das políticas públicas, auxiliando assim o órgão gestor local na formulação, monitoramento, controle, deliberação e fiscalização das políticas públicas (SILVA, et al., 2008).

Allebrandt (2002), observando as experiências existentes no país, relatadas em pesquisas descritivas e analisadas em estudos, propôs uma categorização de três tipos básicos de conselhos: autônomo, paritário e homologatório. O primeiro tipo, autônomo garante a primazia da sociedade civil na composição do espaço. O tipo paritário caracteriza aqueles espaços ou instâncias que em termos de sua composição, definem um equilíbrio de poder entre o Estado e a sociedade, pois cada um ocupa metade das vagas definidas para cada espaço ou instância. O terceiro tipo, homologatório, possui em sua composição a presença majoritária do Estado, característico de alguns conselhos setoriais como os conselhos de defesa civil, conduzidos pela lógica estatal no processo decisório relativo às políticas públicas.

Logo após a promulgação da $\mathrm{CF} / 88$, foram criados vários dos principais conselhos na área das políticas sociais, como o Conselho Nacional de Saúde (Lei n 8.142/90), o Conselho Nacional dos Direitos da Criança e do Adolescente (Lei ${ }^{\circ}$ 8.242/91), o Conselho Nacional de Educação (Lei no 934/96) e o Conselho Nacional de Assistência Social (Lei nº 8.742/93) (VITALE, 2008). Estes Conselhos criados por Lei nas três instâncias públicas são vinculados ao Poder Executivo, sendo sua estrutura pertencente ao órgão da Administração Pública responsável pela coordenação de cada política específica, disponibilizando apoio técnico e administrativo e dotação orçamentária para seu funcionamento. Portanto, os conselhos são espaços privilegiados por proporcionar a participação da sociedade civil nas discussões e decisões em relação ao nível de partilha da riqueza social transferida aos cofres públicos, contribuindo para a democratização da gestão das principais políticas públicas a nível local, pois conforme Bidarra, 2006, p. 49:

\footnotetext{
na condição de espaço público, devem exercitar a partilha equitativa dos processos decisórios entre as representações das organizações da sociedade civil e do segmento governamental, para que as questões, intituladas como públicas, tenham como referente aquilo que está sendo denominado de interesse público, isto é, o conjunto de necessidades e reinvindicações que correspondem aos interesses mais abrangentes de uma coletividade.
}

Nesse sentido, é consensual a construção de uma relação entre a sociedade e o Governo Municipal, superando alguns desafios, como a dimensão política (composição dos conselhos e representatividade) e a dimensão gerencial (bom atendimento da Administração 
Pública, isto é, conhecer processos, competências, dinâmicas para tomada de decisões e para implementação de políticas públicas, de forma a construir um ambiente próprio para negociações). Porém, como ressalta Dagnino (2002), o potencial democratizante dos conselhos mostrou-se diferenciado, conforme cada caso específico. Ao lado do ideal democratizante dos conselhos, uma realidade prática mais problemática surgiu, pois em muitos municípios brasileiros existe uma configuração de poder e controle social distorcida, sendo que os conselhos se limitam a cumprir formalidades, quando não são manipulados pelas elites locais ou partidos políticos. Os governos muitas vezes adotam estratégias de esvaziamento desses espaços e, não raro, instrumentalizam os conselhos para seus objetivos específicos. Diante disso, percebe-se que os conselhos municipais ainda são estruturas em construção, cuja efetivação enquanto órgãos de participação e de concretização da cidadania dependem da superação destes desafios ampliando a relação do Estado com a sociedade.

Para Demo (1994) existe uma pobreza política que fragiliza o processo de cidadania nas políticas sociais e nos espaços democráticos, sendo necessária uma política participativa, que em suas próprias palavras:

Trata-se de iniciativas voltadas ao enfrentamento da pobreza política da população, dentro do reconhecimento de que não se pode enfrentar a pobreza sem o pobre. Política social tem nos pobres não seu alvo, objeto, paciente, mas seu sujeito propriamente, entrando o Estado, ou qualquer outra instância, como instrumentação, apoio, motivação. Nesse espaço, emerge a oportunidade iniludível de formação do sujeito social, consciente e organizado, capaz de definir seu destino e de compreender a pobreza como injustiça social (DEMO, 1994, p. 37).

Dagnino (2002) também compartilha deste pensamento, pois apresenta três características essenciais aos conselhos (composição plural e paritária, natureza deliberativa de suas decisões e seu objetivo de formular e controlar a execução das políticas públicas), ressaltando que atualmente nem sempre esses traços são verificados.

Parafraseando Rover e Fogollari (2005), para que sejam considerados como meio efetivo e concreto de participação popular na gestão pública local, é necessário superar alguns desafios apresentados na realidade das municipalidades. Segundo os autores, um deles trata da cultura política autoritária e clientelista, pautada em privilégios particulares. É primordial a compreensão pela sociedade que a sua participação é necessária, eficiente e decisiva na gestão pública, especialmente quando se estabelece uma boa relação entre os gestores locais e os cidadãos. Desta forma, os Conselhos Municipais funcionam como um espaço de convivência entre os diferentes atores sociais, vindo à tona a visibilidade de suas necessidades e de seus 
problemas, com a busca de soluções concretas para os mesmos e principalmente na efetivação de políticas públicas de qualidade.

Para Sposati (2013), a política de desenvolvimento da representação da população, por meio dos conselhos no processo decisório das políticas públicas é um fator fundamental no rompimento do assistencialismo, ou clientelismo político. A autora destaca que esta realidade está mais presente nos municípios, o que dificulta a legitimidade das políticas públicas que ainda carregam um legado conservador e lesivo à cidadania social.

Outro desafio refere-se à composição paritária dos conselhos, que deve ser tanto numérica quanto qualitativa. Portanto, devem ser excluídos conselheiros que, por exemplo, exercem cargo de confiança na administração pública local, os chamados "apadrinhados" ou "companheiros políticos" e que atendam a serviços priorizados pelos gestores, não representando, dessa forma, os interesses dos usuários, passando, muitas vezes, a agir individualmente e não representando uma entidade ou segmento, estando suscetíveis a pressões políticas. Devem ser estabelecidos critérios para garantir uma igualdade de condições a todos os conselheiros (ROVER; FOGOLLARI, 2005).

Para Souza (2004) em muitos municípios, principalmente de pequeno porte os membros dos conselhos são indicados pelos dirigentes locais, principalmente o Prefeito ou Secretário da pasta, e o seu papel é o de aprovar sem questionar as decisões tomadas pelo poder Executivo local. A autora expõe, portanto, a fragilidade destes espaços, questionando a legitimidade de seus integrantes e principalmente a concentração do poder nas mãos do Executivo, que permanece na política brasileira apesar dos impulsos participativos e descentralizadores que atuaram na elaboração da Constituição de 1988, também conhecida como Constituição Cidadã.

Conforme Rover e Fogollari (2005), com referência à composição qualitativa, faz-se imprescindível a educação permanente dos conselheiros municipais, por meio de cursos presenciais, online, seminários, fóruns, além de participação em Conferências (consideradas outros exemplos de controle social) no intuito de coordenar as ações pertinentes a uma forma mais participativa de construir as políticas públicas, e também uma orientação, tanto para os conselheiros gestores como para os conselheiros usuários, em torno do desenvolvimento de todo o processo, tanto da política como da administração, desenvolvendo-se um comprometimento dos atores sociais nesse trabalho.

Para Tótora e Chaia (2004, p. 219) “capacitar pressupõe um conjunto de conhecimentos e saberes que conferem aos transmissores um poder", ao contrário do aprendizado que ocorre durante processos nos quais o cidadão aprende a reconhecer os seus Barbarói, Santa Cruz do Sul, n.54, p.<6-30>,jul./dez. 2019 
interesses e a diferenciá-los dos outros em disputa. A autonomia é conquistada por meio deste tipo de aprendizado.

O funcionamento dos conselhos depende da gestão municipal, dependência essa que introduz o risco da transformação dos conselhos de instrumento de participação da sociedade na gestão pública em "fonte de legitimação política". Esta ideia se sustenta na análise de alguns documentos legais que instituem formalmente os conselhos o que permite dizer que o funcionamento dos conselhos depende, também, do perfil do Executivo Municipal que detém o poder no momento de sua instituição, quando se decide qual é o formato que a instituição apresentará (TÓTORA; CHAIA, 2004).

O desafio ligado ao caráter deliberativo dos conselhos municipais encontra-se arraigado na já citada tradição clientelista do poder público, devendo ser superado com a compreensão, por parte dos gestores locais, de que a participação popular na definição e na efetivação das políticas públicas é essencial, criando-se um diálogo entre a sociedade civil e os gestores, além de mecanismos de transparência e acessibilidade de todos às informações relativas aos processos. Nesse sentido, quanto maior for a diversidade de meios de comunicação atuantes no local e de cidadãos capazes de fazer uso destes meios, maior será o espaço aberto para os debates públicos, a transparência das decisões e consequentemente a construção do exercício da cidadania (ROVER; FOGOLLARI, 2005).

Outra questão a ser levantada é da garantia dos mecanismos operacionais, ou seja, é preciso que se definam claramente as regras de funcionamento dos conselhos, a periodicidade e a dinâmica das reuniões, a forma de definição dos assuntos a serem tratados na pauta, além da existência de uma logística própria, com uma estrutura física, humana e orçamentária. Deve ser pensado que a utilização das terminologias e siglas comuns no setor público e muitas vezes utilizadas com facilidade por parte dos gestores e técnicos, precisa ser esclarecida aos conselheiros usuários, os quais desconhecem os seus significados e não questionam por vergonha ou comodismo, deliberando ações sem saber ao certo para que servem. Essa falta de informações pode ser compreendida por meio da sociologia das ausências mencionada por Santos (2007), a qual entende que uma percepção hegemônica do mundo produz silêncios e invisibilidade porque é excludente e age ativamente para criar a não existência. Souza (2013) também compartilha deste pensamento quando afirma que toda a realidade social é construída para receber e consumir conhecimento superficial e confundir informação com reflexão. É o que o autor chama de "leitura economicista e redutora da realidade social (SOUZA, 2013, p. 131)". 
As sociedades complexas e modernas demandam a necessidade de utilizar técnicas de controle e planejamento, assim como o uso das tecnologias a seu favor, pois não há como criar uma ordem justa e igualitária sem uma autoridade, poder ou controle utilizado por todos. Vive-se atualmente um constante processo de transformações que interferem na vida social, econômica e política da sociedade, onde a gestão dos governos não pode estar imune a este processo, isto requer participação a qual se efetiva pelo controle social (NOGUEIRA, 2018).

\title{
Políticas de combate à pobreza no Brasil e a atuação dos Conselhos Municipais: Do processo histórico à atualidade
}

As políticas de proteção social estatal vêm sendo executadas no Brasil desde a década de 30 do século passado, no Governo Getúlio Vargas, porém, até a década de 80, a regulação do Estado brasileiro tem sido descontínua, fragmentada e pontual, muito longe de instituir um modelo de Estado de Bem-Estar Social. A rearticulação da sociedade civil nos anos 80 viabilizou a conquista de direitos sociais básicos, legitimados pela Constituição Federal de 1988. "Todo poder emana do povo, que o exerce por meio de representantes eleitos ou diretamente, nos termos da Constituição" (BRASIL, 1988). Este regime democrático de direito que defende a soberania popular, o pluralismo político e a democracia representativa e participativa denominaram-se Constituição Cidadã.

Nestes termos há consenso geral entre estudiosos do poder local (FISCHER, 1996; 2002; SOARES; CACCIA-BAVA, 1998; FEDOZZI, 1999; 2000; DOWBOR, 1995; 1999) de que no Brasil, a partir da constituição de 1988, um processo de descentralização de atuação de Estado teve grande repercussão, mediante uma gama de responsabilidades e atribuições antes desenvolvidas apenas pelo poder central, passando ao âmbito dos governos estaduais e principalmente aos municípios.

Com a descentralização político-administrativa, modificou-se o cenário de implementação das políticas públicas no Brasil, com a transferência de várias responsabilidades do governo federal e estadual para os governos municipais, além de uma autonomia aos municípios na gestão de suas políticas.

\begin{abstract}
A despeito do aparato legal estabelecer as mesmas competências para todos os municípios, em um sistema federativo, a responsabilidade sobre políticas públicas não definidas pela Constituição é resultado da iniciativa própria dos entes federados ou adesão a algum programa proposto por um nível de governo superior que almeja descentralizá-las (ARRETCHE, 2000, p. 47).
\end{abstract}

A autonomia político-administrativa também significou maior responsabilidade e comprometimento dos gestores públicos municipais na oferta dos direitos sociais básicos, 
tendo em vista melhorar a qualidade de vida das pessoas levando em consideração a renda e outras dimensões importantes para avaliar o bem-estar da população, de acordo com padrões vigentes em nossa sociedade. Assim sendo, o art. $6^{\circ}$ da Constituição Federal afirma: "São direitos sociais a educação, a saúde, a alimentação, o trabalho, a moradia, o transporte, o lazer, a segurança, a previdência social, a proteção à maternidade e à infância, a assistência aos desamparados, na forma desta Constituição" (BRASIL, 1988).

No início do novo milênio, o debate sobre a pobreza começa a ter destaque em âmbito internacional com a Agenda 2030, compromisso com o desenvolvimento sustentável assinado por 193 países em setembro de 2015, a qual estabelece que: “a erradicação da pobreza em todas as suas formas e dimensões, incluindo a pobreza extrema, é o maior desafio global e um requisito indispensável para o desenvolvimento sustentável”, com o comprometimento de que "ninguém seja deixado para trás". Em paralelo, a partir da crise financeira de 2008, a Comissão Econômica para a América Latina e o Caribe - CEPAL também define a igualdade como eixo estruturante e norteador das ações para os países da região (BIELSCHOWSKI; TORRES, 2018).

Segundo Vianna (2008), é notória a ascensão de opiniões que políticas e instituições voltadas para os grupos mais vulneráveis podem promover tanto eficiência quanto equidade. A partir disso, os programas de transferência de renda com condicionalidades, focados nos pobres passam a ser implementados no intuito de cumprir funções redistributivas e de alívio da pobreza. Nesse sentido, novas estratégias de proteção social nascem combinando redes de segurança, transferência de renda e foco nos pobres para que sirvam de auxílio nos períodos de crise e de meio de superação da situação de pobreza.

As políticas de combate à pobreza no Brasil passam a fazer parte da agenda política nacional no início dos anos 90, num contexto de estabilização monetária com o Plano Real, porém de restrição econômica para o social, em função de ajustes neoliberais que aliados a estratégias mundiais sugeridas para o combate à pobreza favorecem o surgimento de políticas que priorizam critérios de seletividade, com ênfase nas regiões mais pobres, priorizando territórios e segmentos da população com alta prevalência de pobreza (AZEVEDO, BURLANDY, 2010).

Em 1991 é instituído no Senado Federal o Programa de Garantia de Renda Mínima (PGRM), considerado o pontapé inicial na trajetória da execução das políticas de transferências de rendas e de renda mínima no Brasil. Conforme Silva, Yazbek e Giovanni (2006), esta trajetória vai da instituição de uma renda mínima por meio de diversos programas praticados por Municípios, Estados e pelo Governo Federal, até a criação em 2003, do 
Programa Bolsa Família, objetivando unificar o conjunto de programas desarticulados nos três níveis governamentais.

No ano de 1993 é sancionada a lei no 8.472, Lei Orgânica da Assistência Social reforçando os artigos 203 e 204 da Constituição Federal do Brasil (1988) que estabelecem a proteção à família, à maternidade, à infância, à adolescência, à velhice e às pessoas com deficiência, independentemente de contribuição à seguridade social. Assegura aos dois últimos segmentos um benefício mensal de um salário mínimo, caso não tenham condições de prover a própria manutenção nem de tê-la provida por suas famílias. Destaca-se assim a normatização do Benefício de Prestação Continuada (BPC) como principal benefício implantado. Este prevê a transferência de um salário mínimo para idosos a partir de 65 anos e pessoas com deficiência que possuem renda familiar per capita inferior a $1 / 4$ do salário mínimo. O BPC foi instituído para transferir renda a pessoas idosas e pessoas com deficiência, integrando a Proteção Social Básica no âmbito do Sistema Único de Assistência Social - SUAS, vigente atualmente no Brasil (BRASIL, 1993).

Conforme Allebrandt et al. (2012) as décadas de 80 e 90 se constituem num marco histórico na consolidação das políticas nacionais responsáveis pela articulação das atividades descentralizadas, principalmente no sistema da promoção social, com criação do Sistema Único de Saúde (SUS), da Lei Orgânica da Assistência Social (LOAS) e do Plano Nacional de Educação (PNE). A partir disso, dá-se início a uma nova visão de integralidade das ações, minimizando a noção de caráter compensatório das políticas públicas, abandonando o viés liberal que até então marcou a trajetória dos programas sociais no país.

Azevedo e Burlandy (2010) destacam alguns programas sociais e conselhos de políticas públicas aos quais atribuem importante repercussão no processo histórico das políticas de combate à pobreza no país, entre eles o CONSEA (Conselho de Segurança Alimentar e Nutricional Sustentável), criado em 1996, resultado de mobilização social de alguns setores da sociedade em prol da superação da pobreza, o qual integrou as novas estratégias de enfrentamento à pobreza. Destaca-se o Programa Comunidade Solidária que procurava articular de forma descentralizada e mediante parcerias com a sociedade civil outros programas já existentes em diferentes ministérios para enfrentar a fome e a miséria. $\mathrm{O}$ Planfor (Plano Nacional de Educação Profissional) iniciado em 1996, com o objetivo de qualificar a força de trabalho, elevar o nível de escolaridade da população economicamente ativa, estimular a oferta de emprego e de oportunidade de geração de renda. Também tiveram destaque os programas de inserção produtiva voltados para os trabalhadores desempregados e os inseridos no mercado informal de trabalho. 
Dando prosseguimento a retomada histórica que deu origem aos principais programas sociais do país, o Governo Federal com vistas de garantir os patamares mínimos de renda familiar, melhorando o desempenho escolar e de saúde dos sujeitos assistidos implanta no ano de 1996 o Programa de Erradicação do Trabalho Infantil (PETI), com a finalidade de retirar crianças e adolescentes do trabalho precoce, combinando transferência de renda com a participação em uma jornada ampliada de estudos e atividades correlatas, ou seja, fornecendo dinheiro (bolsa) para a família manter a criança e ao adolescente estudando. Nesta linha, em 2001, após a aprovação pelo Congresso Nacional do Fundo de Combate e Erradicação da Pobreza são lançados importantes programas federais de transferência de renda, por três diferentes ministérios: Bolsa Escola, do Ministério da Educação; Bolsa Alimentação, do Ministério da Saúde; Auxílio Gás, do Ministério de Minas e Energia (AZEVEDO, BURLANDY, 2010).

No ano de 2001 é criado o Cadastro Único para os Programas Sociais, vigente ainda no país com o objetivo de servir como ferramenta de identificação dos beneficiários de baixa renda dos programas do Governo Federal o qual passa a ser utilizado por todos os órgãos públicos federais. Ocorre, porém, que entre 2001 e 2002, os programas de transferência de renda do Governo Federal, como o Programa Bolsa Escola, o Auxílio-Gás, o Bolsa Alimentação e o Programa de Erradicação do Trabalho Infantil (PETI) utilizavam diferentes cadastros para identificar e selecionar o público a ser atendido, dificultando a coordenação das ações, fragmentando o atendimento e apresentando limitações nos resultados pretendidos. A falta de integração das informações possibilitava o acúmulo de benefícios sem que houvesse a garantia da universalização do acesso para todos que precisassem: uma mesma família podia ser beneficiária de dois ou três programas, enquanto que outras, em condição e espaço geográfico próximo, não contavam com nenhum apoio (CURRALERO, 2012).

Esta realidade permaneceu no país até o ano de 2003, onde o destaque foi a unificação dos programas de transferência de renda federais no Programa Bolsa Família - PBF, viabilizando sua expansão nacional para alcançar todas as famílias em situação de pobreza e extrema pobreza em todo o país. Foi instituído em 2004, por meio, da Lei 10.836, de 9/1/2004, e regulamentado pelo Decreto 5.209, de 17/9/2004, sendo na época requisito de participação no PBF a renda mensal de até $\mathrm{R} \$ 77,00$ (extrema pobreza) e $\mathrm{R} \$ 154,00$ (pobreza) nos termos do Decreto $n^{\circ}$ 5.209/04, alterado recentemente pelo Decreto $n^{\circ}$ 8.794/2016 de 29 de junho do ano em curso, os valores de $\mathrm{R} \$ 85,00$ e R \$170,00 (MDS, 2018).

De acordo com Curralero (2012), no processo de unificação dos programas de transferência de renda, a execução local do Programa seria realizada pelo poder público 
municipal com apoio e fiscalização do controle social. Porém, mesmo que o modelo de gestão previsse a participação comunitária e o controle social, os Comitês Gestores Municipais, ganharam muitas atribuições e tiveram seu papel redefinido. Neste período, o controle social do Programa Bolsa Família poderia ser exercido por uma instância que já tivesse essas atribuições em relação aos programas sociais, desde que mantivesse um caráter intersetorial com as pastas de saúde, educação e assistência social. Assim, optou-se por um modelo flexível, que aproveitasse estruturas que já existiam, sem a necessidade de constituição de mais uma instância para o controle social do Programa. Isto se deu até o ano de 2005, onde a adesão dos municípios ao Programa Bolsa Família passa a exigir o requisito da existência formal e do pleno e regular funcionamento de um comitê ou conselho local de controle social.

No que se refere às instâncias de controle social (ICS) do Programa Bolsa Família, foram realizadas algumas pesquisas pelo MDS sendo que em 2009, das 3.220 ICS (57,9\%) que responderam ao questionário, 59,7\% eram Conselhos Municipais de Assistência Social, $38 \%$ eram ICS exclusivas do PBF e 2,3\% de outras áreas, inclusive da área de segurança alimentar e nutricional. Estas instâncias deveriam ter caráter permanente, e exercer as funções de acompanhar, avaliar e fiscalizar a execução do PBF, além de estimular a participação comunitária no controle da execução do Programa (MDS, 2010).

Outra pesquisa recente realizada no ano de 2017 indicou que 91,8\% dos Conselhos Municipais de Assistência Social do país são ICS do Programa Bolsa Família, atuando de forma interdisciplinar nas áreas da assistência social, saúde e educação. Observou-se assim um aumento de 33,9\% do número dos Conselhos Municipais de Assistência Social responsáveis pelo Programa Bolsa Família (MDS, 2018).

Segundo Curralero (2012), todos os municípios e estados possuem formalmente uma instância de controle social, o que não significa, no entanto, seu efetivo funcionamento. Assim, como os Conselhos instituídos por outras políticas públicas, muitas ICS não estão estruturadas e apresentam um mau funcionamento. No ano de 2010 surge a legislação que prevê que 3\% do total de recursos repassados aos municípios para apoiar a gestão local, chamados de índice de Gestão Decentralizada sejam utilizados para a estruturação e funcionamento dos Conselhos Municipais de Assistência Social ou ICS do Programa.

A partir do ano de 2011 passa a ser desenvolvida no Brasil uma estratégia multidimensional coordenada, com objetivos e metas claros e mensuráveis. Trata-se de uma importante iniciativa com base em países que buscam reduzir seus níveis de pobreza e melhorar a qualidade de vida de sua população. Esta estratégia alinhou políticas de diferentes 
áreas e materializou-se no Brasil com o lançamento do Plano Brasil sem Miséria (CAMPEL; MELLO, 2014).

Parafraseando Campelo e Mello (2014), a consolidação de um sistema de proteção social, a implementação de programas sociais como o Bolsa Família e o desenvolvimento de ferramentas inovadoras como o Cadastro Único levaram o Brasil a um novo patamar em políticas sociais. Estas condições proporcionaram solo fértil para a efetivação de uma estratégia nacional multidimensional coordenada para a superação da pobreza em todo o território brasileiro. Nestes mesmos pressupostos, Raichelis (1998) entende que o interesse coletivo e a universalidade devem estar presentes nas ações públicas através da transparência, da participação efetiva do controle social e da democratização e participação dos usuários.

O Plano Brasil sem Miséria apresenta a multidimensionalidade como principal característica, compreendendo a manifestação da pobreza de múltiplas formas além da insuficiência de renda, incluindo insegurança alimentar e nutricional, baixa escolaridade, pouca qualificação profissional, fragilidade de inserção no mundo do trabalho, acesso precário à água, energia elétrica, saúde e moradia, entre outras. Superar a extrema pobreza requer, portanto, a ação intersetorial do Estado. Por isso o Plano Brasil sem Miséria foi organizado de maneira multidimensional, em torno de três eixos de atuação. O primeiro deles é dedicado a proporcionar um rendimento mínimo estável ao público alvo do Plano. O segundo envolve esforços de inclusão produtiva, para oferecer, na cidade e no campo, oportunidades de qualificação, ocupação e geração de renda. O terceiro eixo diz respeito à melhoria do acesso a serviços públicos - especialmente em educação, saúde e assistência social — direcionando a expansão das redes de serviços para as áreas com maior incidência de pobreza extrema. $\mathrm{O}$ Brasil sem Miséria envolve o trabalho de 22 ministérios, além de todos os estados e municípios brasileiros, que juntos executam as cerca de 100 ações do Plano, em vários casos contando com a parceria do setor privado e do terceiro setor (CAMPELO, MELLO, 2014).

Segundo o Relatório de Atividades 2013-2017 do WWP (2018), o Brasil apresentou um longo processo histórico na implantação das políticas de bem-estar social, porém, a continuidade do enfrentamento a pobreza nas últimas décadas, inspirou vários outros países em desenvolvimento e com contextos institucionais, políticos e culturais semelhantes. Em 10 anos, a parcela de pessoas pobres no país caiu de 39,4 por cento em 2003 para 17,0 por cento em 2013. A redução da pobreza chamou atenção para os programas de proteção social do Brasil, que evoluíram em termos orçamentários, teóricos e técnicos, com um papel chave desempenhado pela entrega de programas sociais, assim como o controle social, ainda que 
lentamente ganhou mais espaço na participação e deliberação das ações de enfrentamento a pobreza.

É válido considerar importante neste processo histórico de expansão e unificação das políticas de combate à pobreza a atuação dos conselhos municipais, que mesmo que lentamente foram conquistando espaço, como nos aponta a Pesquisa de Informações Básicas Municipais, realizada pelo IBGE em 1999, evidenciando que a participação da sociedade civil na gestão pública cresceu gradativamente através dos conselhos municipais, que eram cerca de 27 mil nos 5506 municípios que participaram da pesquisa naquele período. Apenas 20 municípios $(0,36 \%$ do total) informaram naquela ocasião a não existência de nenhum tipo de conselho; 33 municípios (0,59\% do total), todos com menos de 50 mil habitantes possuíam apenas um conselho organizado e 252 municípios (4,57\% do total), apenas um com mais de 50 mil habitantes, possuíam apenas dois conselhos. Os 4.669 municípios (85\% do total) que informaram possuir até seis conselhos somam 20.402 ou $75 \%$ dos conselhos informados. Analisando os dados da referida pesquisa, percebe-se uma predominância absoluta dos conselhos municipais de Educação, Saúde e Assistência Social presentes em 91\%, 99\% e 91\%, respectivamente, dos municípios que participaram da pesquisa (IBGE, 1999).

Segundo dados do IBGE com relação aos Conselhos Municipais de Assistência Social, no ano de 2010 haviam instituídos por lei 97,4\%, enquanto que em 2015 os números aumentaram para 99,7\%. Do ano de 2015 a 2017 houve pequena variação, porém permanecendo acima dos 95\%. Outro dado interessante se refere à quantidade de Conselhos Municipais com sede específica para funcionamento sendo que no ano de 2017 mais da metade dos Conselhos $(56,1 \%)$ existentes no país apresentavam sede própria. Houve um ligeiro aumento em relação ao observado em 2016, o que mantém uma tendência histórica dos conselhos de funcionarem em sede especifica, isto é, ter lugar regular para funcionamento. (IBGE, 2015; 2017).

Allebrandt (2003), afirma ser inegável a importância crescente dos conselhos no cenário brasileiro, principalmente a nível municipal, pois ao considerar-se uma média de 10 conselheiros titulares, totalizar-se-ão mais de 270 mil pessoas envolvidas neste processo, ou seja, se somados este número com o mesmo número de suplentes, aproximadamente mais de meio milhão de brasileiros estariam envolvidos nestes espaços de participação da sociedade na gestão pública no nível municipal. Portanto, segundo o autor ainda, a existência formal de conselhos, mesmo que instalados e com conselheiros escolhidos e nomeados, não garante que eles realmente funcionem, ou, mesmo quando funcionam, questiona-se sua eficiência e eficácia enquanto instrumentos de aperfeiçoamento da cidadania. 
Quanto à previsão orçamentária os recursos específicos são aqueles recursos orçamentários do órgão gestor reservados e transferidos regularmente ao conselho para sua manutenção e funcionamento. Em 2017, verificou-se redução dos Conselhos Municipais que possuíam previsão de recursos específicos para sua manutenção e funcionamento (72,9\%), retornando a um patamar similar ao verificado no ano de 2015. Quanto a composição dos conselhos municipais o levantamento demonstrou que desde 2014, a paridade entre governo e sociedade civil, prevista na Lei Orgânica da Assistência Social, vem sendo respeitada, cujos representantes são formados por 50\% de membros da sociedade civil e $50 \%$ de representantes governamentais. Quanto às representações de usuários nos Conselhos Municipais, as maiores representações são de serviços de proteção social com 60,3\%, e de beneficiários do Programa Bolsa Família com 55,9\% (MDS, 2018).

Faz-se necessário avaliar a atuação dos Conselhos Municipais, se constituem-se realmente formuladores ou que pelo menos participem ativamente do processo de formação da agenda das políticas públicas. Estudos têm apontado que, mesmo em anos recentes, muitos dos conselhos municipais não funcionam ou são bastante precários na sua atuação. Por isso é necessário refletir a respeito do funcionamento dos mesmos (ALLEBRANDT, 2002).

\section{Considerações finais}

A consolidação do controle social por meio da participação da sociedade civil nas políticas públicas de combate à pobreza pode ser considerada como um avanço nos últimos trinta anos no campo teórico, da legitimidade e normatização que assim o definiu, porém, no que se refere à sua efetivação nos municípios brasileiros, considera-se este um processo em construção. A legalização do controle social existe na teoria, porém, muito precisa ser construído para superar limitações e promover o exercício democrático mediante a inserção da participação popular na gestão das políticas públicas.

Nessas perspectivas, ao analisar a importância do controle social e a participação dos Conselhos Municipais das políticas de combate à pobreza, destacou-se o processo histórico e as principais conquistas e desafios na consolidação destes arranjos institucionais, ativos após a promulgação da Constituição Federal de 1988 e responsáveis por formular, acompanhar e fiscalizar as principais políticas públicas brasileiras.

A investigação permite concluir que para a construção de um processo de participação da sociedade por meio dos Conselhos Municipais nas esferas administrativas, há necessidade de comprometimento de gestores, técnicos, profissionais, organizações e usuários, que através de suas representações poderão consolidar um sistema de garantia de direitos não apenas no Barbarói, Santa Cruz do Sul, n.54, p.<6-30>, jul./dez. 2019 
campo teórico, mas na prática. Desta forma, pensar em um comprometimento mútuo requer a compreensão de que compromissos devem ser assumidos coletivamente.

Diante disso, há um longo caminho a ser percorrido no sentido de qualificar permanentemente a gestão das políticas públicas, seus profissionais e técnicos, democratizar os Conselhos Municipais, promover campanhas informativas e educativas destinadas à sociedade com linguagem de fácil compreensão e construir estratégias de resistência e questionamento às culturas políticas conservadoras, que mesmo após trinta anos ainda influenciam o processo de democracia, principalmente nos pequenos municípios brasileiros.

Cabe destacar ainda que mesmo com as limitações, muitas conquistas foram consolidadas por meio das legislações federal, estaduais e municipais no que tange as políticas de combate à pobreza e a atuação do controle social. A unificação dos programas sociais está entre um dos principais avanços consolidados no combate à miséria, porém, há um longo caminho a ser percorrido no sentido de avaliar se estas iniciativas estão realmente atingindo seus propósitos de inserção no mercado de trabalho, de maior autonomia dos segmentos assistidos e de promoção e garantia dos demais direitos, sendo os conselhos municipais muito importantes neste processo.

É necessário viabilizar uma qualificação permanente para todas as pessoas envolvidas nas políticas de combate à pobreza (gestores, técnicos, dirigentes de entidades socioassistenciais, funcionários, conselheiros municipais e usuários) informando sobre os novos procedimentos e, principalmente, discutindo sobre os princípios que a norteiam e sobre as suas implicações sociais, éticas e políticas. Este processo precisa ser contínuo, pois a alternância de membros representantes dos Conselhos Municipais ocorre a cada dois a quatro anos, conforme preconiza os regimentos internos de cada conselho.

Acrescenta-se ainda que este processo de educação permanente precisa evidenciar a importância da participação direta de usuários nos conselhos municipais, desmistificando a ideia de incapacidade destes de se auto representarem em mecanismos deliberativos. Faz-se urgente construir um novo sistema que considere a importância do conselheiro municipal enquanto protagonista na gestão das políticas de combate à pobreza e não apenas como mero expectador, velha marca ainda presente em muitas administrações públicas do país.

Tendo em vista os aspectos mencionados, o presente estudo buscou por meio das contribuições científicas e legislações analisadas elucidar a importância do controle social e sua atuação nos últimos trinta anos, sugerindo uma reflexão e análise do leitor quanto à efetividade destes espaços e seu real poder de decisão. No entanto, não esgotando a discussão com relação à temática investigada, percebe-se a necessidade de continuidade de estudos que Barbarói, Santa Cruz do Sul, n.54, p.<6-3o , jul./dez. 2019 
possam ofertar programas de educação permanente voltados ao coletivo, especificando as responsabilidades e competências de todos os atores sociais envolvidos, objetivando assim, solidificar e fortalecer a participação do controle social por meio dos Conselhos Municipais nas políticas de combate à pobreza.

\title{
THE IMPORTANCE OF SOCIAL CONTROL AND PARTICIPATION OF CITY COUNCILS IN POVERTY POLICIES
}

\begin{abstract}
This article aims to reflect on the importance of social control and the participation of municipal councils in policies to combat poverty. It highlights the historical process and the main achievements and challenges in the consolidation of these institutional arrangements, active after the promulgation of the Federal Constitution of 1988 and responsible for formulating, monitoring and overseeing Brazilian public policies. To meet the proposed challenge, the methodological approach relies on a qualitative approach, with bibliographic and documentary research based on classical and contemporary theoretical contributions that address the theme, classifying the study as exploratory research. The clipping used was the Federal Constitution from 1988 until the current context of 2019. In an attempt to promote greater reflections on the subject, the relationship between legal norms and their practical implementation is problematized in this work, through the analysis of different theoretical conceptions and the historical process of the participation of the Municipal Councils in the fight against poverty policies. The results of the research indicate that even being consolidated through Legislation, there are many challenges in order to effect the participation of social control in the management of anti-poverty policies. Legalization exists in theory, but much needs to be built to overcome limitations and promote the democratic exercise of the population through the Municipal Councils in the management of public policies.
\end{abstract}

Keywords: Social Control. Public Policy. Municipal Councils.

\section{LA IMPORTANCIA DEL CONTROL SOCIAL Y LA PARTICIPACIÓN DE LOS AYUNTAMIENTO EN LAS POLÍTICAS DE POBREZA}

\section{Resumen}

Este artículo tiene como objetivo reflexionar sobre la importancia del control social y la participación de los consejos municipales en las políticas de lucha contra la pobreza. Destaca el proceso histórico y los principales logros y desafíos en la consolidación de estos arreglos institucionales, activos después de la promulgación de la Constitución Federal de 1988 y responsables de formular, monitorear y supervisar las políticas públicas brasileñas. Para enfrentar el desafío propuesto, el enfoque metodológico se basa en un enfoque cualitativo, con investigación bibliográfica y documental basada en contribuciones teóricas clásicas y contemporáneas que abordan el tema, clasificando el estudio como investigación exploratoria. El recorte utilizado fue la Constitución Federal desde 1988 hasta el contexto actual de 2019. En un intento por promover mayores reflexiones sobre el tema, la relación entre las normas legales y su implementación práctica se problematiza en este trabajo, a través del análisis de diferentes concepciones teóricas y el proceso histórico de la participación de los Consejos Municipales en la lucha contra las políticas de pobreza. La legalización existe en teoría, pero es necesario construir mucho para superar las limitaciones y promover el ejercicio 
democrático de la población a través de los Consejos Municipales en la gestión de las políticas públicas.

Palabras clave: Control social. Políticas públicas. Consejos municipales.

\section{REFERÊNCIAS}

ALLEBRANDT, S. L. A participação da sociedade na gestão pública. Ijuí: Ed.Unijuí, 2002.

Conselhos Municipais: potencialidades e limites para a efetividade e eficácia de um espaço público para a construção da cidadania interativa. UFJF, 2003. Disponível em <http://www.ufjf.br/virgilio_oliveira/files/2014/10/Texto-18-Allebrandt-2003.pdf>. Acesso em 04 de Fevereiro de 2019.

Alebrandt, S. L.; MARIN FILHO, C. J.; CERATTI, L. L. Políticas Públicas Sociais e de Desenvolvimento Local no Noroeste Gaúcho: Percepções sobre seus impactos e Limitações. In: CANÇADO, Airton C.; TENÓRIO, Fernando G.; SILVA JR, Jeová T (Org). Gestão Social: Aspectos Teóricos e Aplicações. Ijuí: Ed. Unijuí, 2012. p. 193-219.

ARRETCHE, M. Estado Federativo e Políticas Sociais: determinantes da descentralização. São Paulo: FAPESP, 2000.

AZEVEDO, D. C; BURLANDY, L. Política de Combate à Pobreza no Brasil, concepções e estratégias. Rev. Katál. Florianópolis v. 13 n. 2 p. 201-209 jul./dez. 2010.

BIDARRA, Z. S. Conselhos Gestores de Políticas Públicas: uma reflexão sobre os desafios para a construção dos espaços públicos. Serviço Social e Sociedade, São Paulo, Cortez, n. 88, nov. 2006.

BIELSCHOWSKY, R.; TORRES, M. Desarrollo e igualdad: el pensamiento de la CEPAL en su séptimo decenio. Textos seleccionados del período 2008-2018. Colección 70 años. Comissão Econômica para a América Latina e o Caribe (CEPAL), Santiago, 2018.

BRASIL. Constituição da República Federativa do Brasil: atualizada até a Emenda Constitucional no 90, Brasília, DF, 05 de outubro de 1988. Disponível em: <https://www2.senado.leg.br/bdsf/bitstream/handle/id/...CF88_Livro_EC91_2016.pdf > Acesso em 05 de Janeiro de 2019.

Lei $n^{\circ}$ 8.742, de 07 de dezembro de 1993. Dispõe sobre a Lei Orgânica da Assistência Social e dá outras providências. Brasília, DF. Disponível em: <http://www.planalto.gov.br/ccivil_03/Leis/L8742.htm>. Acesso em: 06 de Fevereiro de 2019.

Ministério do Desenvolvimento Social e Combate à Fome. Protocolo de Gestão Integrada de Serviços, Benefícios e Transferências de Renda no âmbito do Sistema Único de Assistência Social - SUAS. Comissão Intergestores Tripartite. Brasília, 2010. Ministério do Desenvolvimento Social. Secretaria Nacional de Assistência Social. Censo Suas dos anos de 2010 a 2017, Brasília, 2018. 
CAMPELLO, T.; MELLO, J. O processo de formulação e os desafios do Plano Brasil sem Miséria: por um país rico e com oportunidades para todos. In: CAMPELLO, Tereza; FALCÃO, Tiago; COSTA, Patricia Vieira da (Orgs.). O Brasil sem miséria. Brasília: MDS, 2014.

CARVALHO, M. C. B. Assistência Social: uma política pública convocada e moldada para constituir-se em "governo paralelo da pobreza". Serviço Social e Sociedade, São Paulo, n. 46, p. 86-103, dez. 1994.

CORREIA, M. V. C. Que controle social na política de Assistência Social. Serviço Social e Sociedade, São Paulo, Cortez, n. 72, set. 2002.

Controle Social. Dicionário da Educação Profissional em Saúde $2^{\mathrm{a}}$ ed. Org.

PEREIRA, I. B; LIMA, J. C. F. EPSJV, Rio de Janeiro: Editora Fiocruz, 2008, p. 66-73.

Disponível em: <http://www.epsjv.fiocruz.br/upload/d/Controle_Social_-_rec.pdf >. Acesso em 11 de Janeiro de 2019.

CURRALERO, C. R. B. O Enfrentamento da pobreza como desafio para as políticas sociais no Brasil: uma análise a partir do Programa Bolsa Família, Tese de Doutorado, UNICAMP, Campinhas, SP, 2012.

DAGNINO, E. Sociedade civil, espaços públicos e a construção democrática no Brasil: limites e possibilidades. In: Paulo: Paz e Terra, 2002, p.279-301. (Org.). Sociedade civil e espaços públicos no Brasil. São

DEMO, P. Política social, educação e cidadania. Campinas: Papirus, 1994.

DOWBOR, L. O poder local diante dos novos desafios globais. In: Fundação Prefeito Faria Lima. O município no século XXI: cenários e perspectivas. São Paulo: Cepam, 1999.

Disponível em: <http://www.cepam.sp.gov.br/v11/biblioteca/publicacoes_dowload.asp>. Acesso em 16 de Janeiro de 2019.

Da globalização ao poder local: a nova hierarquia dos espaços. Artigos Online. São Paulo, 1995. Disponível em: <http://dowbor.org/5espaco.asp >. Acesso em 16 de Janeiro de 2019.

FEDOZZI, L. O poder da aldeia: gênese e história do orçamento participativo de Porto Alegre. Porto Alegre: Tomo Editorial, 2000.

Orçamento Participativo: reflexões sobre a experiência de Porto Alegre. $2^{\mathrm{a}} \mathrm{Ed}$. Porto Alegre: Tomo Editorial; Rio de Janeiro: Fase - IPPUR, 1999.

FISCHER, T. Gestão Contemporânea, cidades estratégicas: aprendendo com fragmentos e reconfigurações do local. In: (Org.). Gestão Contemporânea, cidades estratégicas e organizações locais. Rio de Janeiro: Ed. FGV, 1996.

(Org.). Gestão do desenvolvimento e poderes locais: marcos teóricos e avaliação. Salvador: Casa da Qualidade, 2002. 
GRAMSCI, A. Maquiavel, a política e o Estado Moderno. Rio de Janeiro: Civilização Brasileira, 1978.

GIL, A. C. Como elaborar projetos de pesquisa. 6. ed. São Paulo: Atlas, 2017.

IAMAMOTO, M.; CARVALHO, R. Relações Sociais e Serviço Social no Brasil: esboço de uma interpretação histórico-metodológica. São Paulo: Cortez, 1982.

. Relações Sociais e Serviço Social no Brasil: esboço de uma interpretação histórico-metodológica. 6 aed. São Paulo: Cortez/Celats, 1988.

IBGE - Coordenação de População e Indicadores Sociais. Perfil dos Municípios Brasileiros. Pesquisa de Informações Básicas Municipais. Suplemento de assistência social. 1999. Brasil.

Perfil dos Municípios Brasileiros. Pesquisa de Informações Básicas Municipais. Suplemento de assistência social. 2015. Brasil.

Perfil dos Municípios Brasileiros. Pesquisa de Informações Básicas Municipais. Suplemento de assistência social. 2017. Brasil.

MANNHEIM, K. Sociologia Sistemática: uma introdução ao estudo de sociologia. 2. Ed. São Paulo: Pioneira, 1971.

NOGUEIRA, M. A. Controle/Controle Social. In: Dicionário de Políticas Públicas, Org. DI GIOVANNI, G.; NOGUEIRA, M. A.; 3. Ed., São Paulo, Editora UNESP, 2018.

PAES DE PAULA, A. P. Administração pública brasileira entre o gerencialismo e a gestão social. Revista de Administração de Empresas, v. 45, n.1, 2005. Disponível em: <www.scielo.br/pdf/rae/v45n1/v45n1a05>. Acesso em 10 Janeiro de 2019.

PIMENTA, M. V. A. Teoria da Constituição. Belo Horizonte: Del Rey, 2007.

RAICHELIS, R. Esfera Pública e Conselhos de Assistência Social: caminhos da construção democrática. São Paulo: Cortez Editora, 1998.

ROVER, O. J.; FOGOLARI, H. A gestão social para o desenvolvimento local em municípios essencialmente rurais. Dossiê Gestões Públicas Democráticas e Experimentos Participativos, Chapecó, n. 18, p. 47-70, jun. 2005.

SANTOS, B. S. Renovar a teoria crítica e reinventar a emancipação social. São Paulo: Boitempo, 2007.

SILVA, M. O. S.; YASBEK, M. C.; GIOVANNI, G. A política social brasileira no século XXI: a prevalência dos programas de transferência de renda. $2^{\mathrm{a}}$ ed. São Paulo: Cortez, 2006.

SILVA, V. R. et al. Controle Social no Sistema Único de Assistência Social: propostas, concepções e desafios. Revista Textos \& Contextos, Porto Alegre, v. 07, n. 02, p. 250-265, jul./dez. 2008. 
SOARES, J. A.; CACCIA-BAVA, S. (Orgs.). Os desafios da gestão municipal democrática. São Paulo: Cortez, 1998.

SOUZA, C. Governos locais e gestão de políticas sociais universais. São Paulo em Perspectiva, São Paulo, v. 18, n. 2, p. 27-41, 2004. Disponível em:

<http://www.scielo.br/pdf/spp/v18n2/a04v18n2.pdf>. Acesso em 16 Janeiro de 2019.

SOUZA, J. Em defesa da Sociologia: O Economicismo e a Invisibilidade das Classes

Sociais. Revista Brasileira de Sociologia, v. 01, n. 01, Jan/Jul 2013.

SPOSATI, A. Os 20 anos de LOAS: a ruptura com o modelo assistencialista. In: CRUZ, José Ferreira da Crus [et al]. 20 anos da Lei Orgânica de Assistência Social. Ministério do Desenvolvimento Social e Combate à Fome: Brasília: MDS, 2013.

TÓTORA, S. \& CHAIA, V. 2004. Conselhos municipais e a institucionalização da participação política: a Região Metropolitana de São Paulo. In : SANTOS JR., O. A.; QUEIROZ, L. C. \& AZEVEDO, S. (orgs.). Governança democrática e poder local: a experiência dos conselhos municipais no Brasil. Rio de Janeiro: Revan.

VIANNA, M. L. W. A nova política social no Brasil: uma prática acima de qualquer suspeita teórica? Revista Praia Vermelha, Rio de Janeiro, v. 18, n. 1, p. 120-145, 2008.

VITALE, D. Democracia e participação na gestão de políticas públicas: teoria e prática. Bahia Análise \& Dados, Salvador, v.17, n.4, p. 1147-1154, jan./mar. 2008.

WWP (World Without Poverty) Mundo sem Pobreza: Iniciativa Brasileira de Apredizagem, MDS, Série Brasil sem Miséria, 2018. Disponível em: $<\mathrm{http}$ //socialprotection.org/sites/default/files/publications_files/02.\%20BSM\%20\%20Introdu cao.pdf $>$. Acesso em 01 de Fevereiro de 2018.

YAZBEK, M. C. As ambiguidades da Assistência Social Brasileira após Dez anos de LOAS. In: Serviço Social e Sociedade, São Paulo V.77, p. 11-29, 2004.

Data de recebimento: 19/07/2019

Data de aceite: $13 / 11 / 2019$

Sobre os autores:

Fabiana Zanardi é Assistente Social, Especialista em Saúde Coletiva: Ênfase em Sanitarismo pela Universidade Regional Integrada do Alto Uruguai e das Missões URI - Campus de Frederico Westphalen e Mestranda em Desenvolvimento Regional pelo Programa de PósGraduação em Desenvolvimento Regional pela Universidade Regional do Noroeste do Estado do Rio Grande do Sul - UNIJUÍ, área de Políticas Públicas e Gestão Social (2018). Pesquisadora do Grupo GPDeC/UNIJUÍ, Bolsista Parcial UNIJUÍ. Endereço Eletrônico: fab.zan@hotmail.com

Airton Adelar Mueller é Professor/pesquisador no Programa de Mestrado e Doutorado em Desenvolvimento Regional na Universidade Regional do Noroeste do Estado do Rio Grande 
do Sul - Brasil, onde coordena a Linha de Pesquisas em Políticas Públicas e Gestão Social. Doutor em Sociologia pela Freie Universität Berlin, Alemanha (2015). Título revalidado no Brasil pela Universidade de São Paulo - USP. Mestre em Desenvolvimento Regional (2007) e graduado em Estudos Sociais/História (2004) pela Universidade de Santa Cruz do Sul, Brasil. Realizou estágio pós-doutoral PNPD-CAPES junto ao Programa de Pós-Graduação Mestrado e Doutorado em Desenvolvimento Regional na Universidade Regional do Noroeste do Estado do Rio Grande do Sul - UNIJUÍ, Brasil, 2015-2017. Endereço Eletrônico: airton.mueller@unijui.edu.br

Moisés de Oliveira Matusiak é Professor do curso de graduação em Direito da Universidade de Cruz Alta - UNICRUZ. Doutorando em Desenvolvimento Regional na Universidade Regional do Noroeste do Estado do Rio Grande do Sul - UNIJUÍ. Mestre em Direito (2015) e Especialista em Direito Penal e Processo Penal (2013) pelo Centro Universitário Ritter dos Reis - UNIRITTER. Endereço Eletrônico: moisesmatusiak@gmail.com

Edi Branco da Silva é graduada em Administração pela Sociedade Educacional Três de Maio, formação em Coaching e Mentoring pela Retorno Consultoria e Carreira. Possui especialização MBA Executivo em Gestão Empresarial, Mestranda em Desenvolvimento Regional pela Universidade Regional do Noroeste do Estado do Rio Grande do Sul, área de Políticas Públicas e Gestão Social (2018). Pesquisadora do Grupo GPDeC/UNIJUÍ, Bolsista Capes. Endereço Eletrônico: edybranco@yahoo.com.br 